\title{
The Ecstasy and Agony of Assay Interference Compounds
}

$\mathrm{T}$ he ecstasy of discovering a new hit from screening can lead to a highly productive research effort to discover new bioactive compounds. However, in too many cases this ecstasy is followed by the agony of realizing that the compounds are not active against the desired target. Many of these false hits are Pan Assay INterference compoundS (PAINS) ${ }^{1}$ or colloidal aggregators. ${ }^{2}$ Whether the screen is conducted in silico or in the laboratory and whether screening libraries, natural products, or drugs are used, all discovery efforts that rely on some form of screening to identify bioactivity are susceptible to this phenomenon. Studies that omit critical controls against experimental artifacts caused by PAINS may waste years of research effort as useless compounds are progressed. ${ }^{3-8}$ The American Chemical Society (ACS) is eager to alert the scientific community to this problem and to recommend protocols that will eliminate the publication of research articles based on compounds with artificial activity. This editorial aims to summarize relevant concepts and to set the framework by which relevant ACS journals will address this issue going forward.

Alarmingly, up to $80-100 \%$ of initial hits from screening can be artifacts if appropriate control experiments are not employed. The source of this artificial behavior has been thoroughly summarized in the literature. ${ }^{9-12}$ Misleading assay results can arise through a variety of mechanisms including covalent protein reactivity, ${ }^{13}$ redox activity, interference with assay spectroscopy, ${ }^{14-16}$ membrane disruption, ${ }^{17}$ decomposition in buffers, ${ }^{18}$ and the formation of colloidal aggregates. ${ }^{2,19,20}$ If not properly controlled, colloidal aggregation is perhaps the most common artifact from high-throughput screening: between 1 and $3 \%$ of molecules in many screening libraries will aggregate at relevant concentrations and up to $95 \%$ of "hits" identified from a screen can be assigned as aggregates, ${ }^{21}$ and the colloids that they form inhibit, ${ }^{20-22}$ or occasionally activate, proteins. ${ }^{23}$ PAINS molecules can be synthetic in origin or derived from natural products; the latter have been termed Invalid Metabolic PanaceaS, or IMPS. ${ }^{24}$ Even marketed drugs can aggregate and may also contain PAINS chemotypes. Over 60 FDA-approved and worldwide drugs contain PAINS chemotypes, ${ }^{25}$ and about the same number have been shown to aggregate. ${ }^{26}$ Although some drugs can contain PAINS and can aggregate at micromolar concentrations, such examples do not imply that any molecule that acts via a PAINS or aggregation mechanism can become a drug. Hence, noting or "flagging" any PAINS-containing hits and performing detailed follow-up experiments are essential to validate that the function of the molecule is as expected prior to discarding it from further consideration. ${ }^{27}$ However, it is important to realize that no PAINS-containing drug has ever been developed starting from a protein-reactive PAINS target-based screening hit. ${ }^{28}$

Publicly available filters can help to identify PAINS and aggregators (e.g., http://zinc15.docking.org/patterns/home, http://www.cbligand.org/PAINS/, http://fafdrugs3.mti.univparis-diderot.fr/, http://advisor.docking.org), but these tools will not comprehensively identify all compounds with PAINS- like or colloidal behavior, and they may also inappropriately label a compound as an artifact when it is not. ${ }^{29,30}$ Any in silico filter should therefore be augmented by experimental follow-up, a detailed practical guide for which has recently been published. ${ }^{31}$ Such validation experiments include classic dose response curves, lack of incubation effects, imperviousness to mild reductants, and specificity versus counter-screening targets. If a molecule is flagged as a potential PAINS or aggregator using published patterns but is well-behaved by these criteria, it may be a true, well-behaved ligand. Ultimately, genuine SAR combined with careful mechanistic study provides the most convincing evidence for a specific interaction. ${ }^{30,32}$ Covalent and spectroscopic interference molecules act via specific physical mechanisms, for which controls are known (see section c). Colloidal aggregation, fortunately, is readily identified by rapid mechanistic tests and by counter-screening (see section d).

While this editorial focuses on target-based screening, the issue of PAINS is also relevant to phenotypic screening and to drug repurposing studies, and it is obvious that rational interpretation and optimization of cellular activity with an inherently reactive chemotype may be difficult if not impossible. ${ }^{33}$ Further, membrane perturbation becomes an additional promiscuity mechanism ${ }^{17}$ and is very likely a contributing reason for the prevalence of IMPS in scientific databases and literature. ${ }^{24}$ Whether PAINS and/or IMPS motifs are present, the common requirement of comprehensive and logical SAR is of paramount importance for any phenotypic screening hit, and optimization to well under micromolar levels of activity should be demonstrated.

\section{CONTROLS FOR ARTIFACTUAL ASSAY ACTIVITY}

a. Irreversible Inhibitors. Unless one is specifically screening for selective covalent modifiers, irreversible inhibitors-either acting themselves through a reactive center or representing the activity of an impurity-are typically undesired artifacts. A rapid counter-screen for irreversible inhibition is to incubate the target protein at $5 \times$ its normal assay concentration and the hit at $5 \times$ its apparent $\mathrm{IC}_{50}$, and after incubation, dilute them 10 -fold (other $\mathrm{IC}_{50}$ ratios may of course be chosen). If inhibition is rapidly reversible, the inhibition on dilution should drop to about $33 \%$ of full inhibition on dilution (about $40 \%$ of the value at $5 \times$ the $\mathrm{IC}_{50}$ ). If dilution changes the inhibition little, it supports covalent activity. Legitimate slow off-rate inhibition is another alternative, but such molecules are rare among initial screening hits. This experiment will only work for soluble proteins, but related experiments to measure off-rate may be adapted for membrane proteins. More generally, a timedependent increase in apparent inhibitory potency suggests irreversible binding. Lack of dissociation determined by direct measurement of ligand kinetics using biophysical methods such as surface plasmon resonance also demonstrates irreversibility. Inhibitors with electrophiles need not react with target proteins

Published: February 28, 2017 
to be problematic. Their reversible reactions with cellular thiolates, such as glutathione, can render them inactive in cells. ${ }^{34}$ It may be necessary to use several techniques to differentiate between covalent/nonreversible, covalent/reversible, and pseudoirreversible inhibitors.

b. PAINS Molecules. The chemotypes represented by these molecules often occur among promiscuous molecules that fail to progress. Most PAINS are dominated by a few chemotypes that are readily recognized. ${ }^{29}$ Several in silico tools are available to identify these groups, including at http://www.cbligand.org/ PAINS/, http://zinc15.docking.org/patterns/home, and http://fafdrugs3.mti.univ-paris-diderot.fr/. PAINS molecules act through several interference mechanisms, including all those described herein, and there is no single diagnostic test for the entire suite of bad actors. We recommend counterscreening the molecule against unrelated targets, as well as determining whether it competes with a ligand known to bind to the site and whether its concentration-response curves are well-behaved (e.g., has a Hill coefficient close to 1, or a strong mechanistic reason to differ from 1). PAINS frequently make it through to peer-reviewed publications, as protein reactivity can be subtle and selectivity over counter-screens may be exhibited. Therefore, thorough and logical SAR is the most important criterion that distinguishes a PAIN from a non-PAIN. As for any screening hit, literature review for evidence of chemotype promiscuity is essential, and in this context, Badapple ${ }^{35}$ is an excellent resource that merits special mention.

c. Spectroscopic Interference Compounds and Compounds That Inhibit Reporter Enzymes. Compounds that absorb light or fluoresce in a region used to measure activity, or compounds that inhibit a reporter enzyme, like luciferase, ${ }^{12,14-16}$ can appear to be active, but in fact are simply interfering with the assay. Spectroscopic interference should change linearly with concentration, following Beer's law, rather than log-linearly as in a single site isotherm. Inhibitors of the reporter enzyme require a counter-screen. For all assay detection methods, it is critical to determine the propensity of screening hits to interfere with the detection signal by running an artifact or interference assay measuring the effect of the compound on the signal detection reagents.

d. Colloidal Aggregation. Perhaps the largest single source of artifacts in early discovery is colloidal aggregation by small molecules. ${ }^{26}$ These particles, typically between 50 and $1000 \mathrm{~nm}$ in radius, nonspecifically adsorb protein, partially denaturing them. About two percent of molecules in a typical screening deck will aggregate at relevant concentrations, ensuring that hits reflecting colloid formation dominate in screens, both virtual and empirical, which do not control for them. Fortunately, molecules that act as aggregators can sometimes be recognized computationally (http://advisor. docking.org), 2,21,22 and better still, this mechanism may be readily controlled experimentally:

i. If activity can be attenuated by small amounts of nonionic detergent, the compound is likely an aggregator. A typical protocol involves $0.01 \% \mathrm{v} / \mathrm{v}$ freshly prepared Triton X-100 or $0.025 \% \mathrm{v} / \mathrm{v}$ Tween $-80^{36}$ for membrane or cell assays.

ii. Direct observation of particles in the 50 to $1000 \mathrm{~nm}$ size range by dynamic light scattering (DLS). Formation of particles does not guarantee promiscuous inhibition, but it is a worrying sign. iii. For cell-based assays, colloidal particles can be precipitated by centrifugation of the medium before the assay is run. If the compound is much more effective before spin-down, it suggests colloidal aggregation. As an aside, it is critical to demonstrate that the compound is active at concentrations substantially lower than those producing cellular toxicity to show that the apparent activity is not simply due to cell death. In activity assays in which cytotoxicity is the desired end-point (e.g., anticancer assays), the compound should show high selectivity for cancer over normal cells.

iv. Noncompetitive inhibition with high Hill slopes. There are classical reasons for noncompetitive inhibition and for cooperative binding, but the latter is rare in early discovery and the two together suggest aggregation.

v. Attenuation of inhibition by increasing target concentration. Except when the receptor concentration to $K_{\mathrm{i}}$ ratio is high, ${ }^{37-39}$ increasing receptor concentration should not affect inhibition for well-behaved inhibitors. However, inhibitory activity will be much reduced for colloidal aggregators, and an increase in the steepness of the response curve will be observed. This experiment can only be used for soluble proteins.

vi. Potential aggregators can be counter-screened for inhibition of enzymes like AmpC $\beta$-lactamase, trypsin, or malate dehydrogenase, which are highly sensitive to compound aggregation. ${ }^{40}$ These enzymes are convenient because perturbations like detergent addition, which are not well-tolerated by some systems, are readily tolerated by these enzymes.

Regardless of whether or not one suspects that a molecule is a bad actor, detailed biophysical testing of new inhibitors for mechanism is always useful and can accelerate a drug discovery campaign. There is an understandable tendency to fall in love with early hits, but hard experience ${ }^{41}$ shows that early hits can be fool's gold and distract from more promising molecules that emerge later. Measuring and publishing full concentrationresponse curves is a simple but crucial way to retain focus on only the most interesting molecules; much can be learned from the steepness of the curve and how well it is sampled. ${ }^{42}$ A step further is to measure the full binding constant, either through determination of the $K_{\mathrm{i}}$ by kinetic analysis, by radioligand displacement, or by reporter-free methods such as isothermal titration calorimetry, surface plasmon resonance, or related techniques. Here too, full curves should be measured and reported.

In light of these concerns, the participating ACS journals plan to uphold the standards above to ensure that all compounds for which activity is reported demonstrate activity commensurate with expectations (i.e., the compound is binding to the expected pocket and accompanied by thorough SAR). Active compounds from any source must be examined for known classes of assay interference compounds, and this analysis must be provided in the general experimental section. For compounds with potential assay interference liability, firm experimental evidence must be presented from at least two different assays, both of which report that the compounds are specifically active and that the apparent activity is not an artifact. Other issues that need to be considered in this context are the purity of the compound, stability in assay buffers, cysteamine or glutathione (GSH) reactivity, and a review of the literature for previous activities reported for the compound or 
compound class. The goal here is not to eliminate a priori all compounds that may resemble PAINS or colloidal aggregators - this cannot always be done to $100 \%$ confidence, and even molecules that appear to have progressable SAR can still be artifacts. ${ }^{32}$ Rather, the goal is to ensure that compounds with an inbuilt tendency toward this behavior are well-vetted before publication, or indeed before submission for publication. This will diminish the number of articles that mislead the field. These new standards will bring clarity to medicinal chemistry and chemical biology and further ensure the already high level of science published in ACS journals.

Courtney Aldrich, Editor-in-Chief ${ }^{-1}$

ACS Infectious Diseases

Carolyn Bertozzi, Editor-in-Chief ${ }^{\circ}$

ACS Central Science

Gunda I. Georg, Editor-in-Chief ${ }^{(1)}$

Journal of Medicinal Chemistry

Laura Kiessling, Editor-in-Chief ${ }^{()}$

ACS Chemical Biology

Craig Lindsley, Editor-in-Chief ${ }^{\circ}$

ACS Chemical Neuroscience

Dennis Liotta, Editor-in-Chief ${ }^{\circledR}$

ACS Medicinal Chemistry Letters

Kenneth M. Merz, Jr., Editor-in-Chief

Journal of Chemical Information and Modeling

Alanna Schepartz, Editor-in-Chief (i)

Biochemistry

Shaomeng Wang, Editor-in-Chief ${ }^{-1}$

Journal of Medicinal Chemistry

\section{AUTHOR INFORMATION}

\section{ORCID $\odot$}

Courtney Aldrich: 0000-0001-9261-594X

Carolyn Bertozzi: 0000-0003-4482-2754

Gunda I. Georg: 0000-0002-8900-9460

Laura Kiessling: 0000-0001-6829-1500

Craig Lindsley: 0000-0003-0168-1445

Dennis Liotta: 0000-0002-7736-7113

Kenneth M. Merz Jr.,: 0000-0001-9139-5893

Alanna Schepartz: 0000-0003-2127-3932

Shaomeng Wang: 0000-0002-8782-6950

\section{Notes}

Adapted from an article by Brian K. Shoichet and John J. Irwin with input from Jonathan Baell, Jürgen Bajorath, Jon Hawkinson, Guido Pauli, and Michael A. Walters. This editorial appears in ACS Infectious Diseases, ACS Central Science, Journal of Medicinal Chemistry, ACS Chemical Biology, ACS Chemical Neuroscience, ACS Medicinal Chemistry Letters, Journal of Chemical Information and Modeling, and Biochemistry.

Views expressed in this editorial are those of the authors and not necessarily the views of the ACS.

\section{REFERENCES}

(1) Baell, J.; Walters, M. A. Chemistry: Chemical con artists foil drug discovery. Nature 2014, 513, 481-483.

(2) McGovern, S. L.; Caselli, E.; Grigorieff, N.; Shoichet, B. K. A common mechanism underlying promiscuous inhibitors from virtual and high-throughput screening. J. Med. Chem. 2002, 45, 1712-1722.
(3) Allen, W. J.; Yi, H. A.; Gochin, M.; Jacobs, A.; Rizzo, R. C. Small molecule inhibitors of HIVgp41 N-heptad repeat trimer formation. Bioorg. Med. Chem. Lett. 2015, 25, 2853-2859.

(4) Dong, X.; Zhou, X.; Jing, H.; Chen, J.; Liu, T.; Yang, B.; He, Q.; $\mathrm{Hu}, \mathrm{Y}$. Pharmacophore identification, virtual screening and biological evaluation of prenylated flavonoids derivatives as PKB/Akt1 inhibitors. Eur. J. Med. Chem. 2011, 46, 5949-5958.

(5) Zhong, Z.; Liu, L. J.; Dong, Z. Q.; Lu, L.; Wang, M.; Leung, C. H.; Ma, D. L.; Wang, Y. Structure-based discovery of an immunomodulatory inhibitor of TLR1-TLR2 heterodimerization from a natural product-like database. Chem. Commun. (Cambridge, $U$. K.) $2015,51,11178-11181$.

(6) Mohammed, A.; Al-Numair, K. S.; Balakrishnan, A. Docking studies on the interaction of flavonoids with fat mass and obesity associated protein. Pak. J. Pharm. Sci. 2015, 28, 1647-1653.

(7) Park, H.; Kim, S. Y.; Kyung, A.; Yoon, T. S.; Ryu, S. E.; Jeong, D. G. Structure-based virtual screening approach to the discovery of novel PTPMT1 phosphatase inhibitors. Bioorg. Med. Chem. Lett. 2012, 22, $1271-1275$

(8) Brecher, M.; Chen, H.; Liu, B.; Banavali, N. K.; Jones, S. A.; Zhang, J.; Li, Z.; Kramer, L. D.; Li, H. Novel broad spectrum inhibitors targeting the flavivirus methyltransferase. PLoS One 2015, 10, $\mathrm{e} 0130062$.

(9) Arrowsmith, C. H.; Audia, J. E.; Austin, C.; Baell, J.; Bennett, J.; Blagg, J.; Bountra, C.; Brennan, P. E.; Brown, P. J.; Bunnage, M. E.; Buser-Doepner, C.; Campbell, R. M.; Carter, A. J.; Cohen, P.; Copeland, R. A.; Cravatt, B.; Dahlin, J. L.; Dhanak, D.; Edwards, A. M.; Frederiksen, M.; Frye, S. V.; Gray, N.; Grimshaw, C. E.; Hepworth, D.; Howe, T.; Huber, K. V.; Jin, J.; Knapp, S.; Kotz, J. D.; Kruger, R. G.; Lowe, D.; Mader, M. M.; Marsden, B.; Mueller-Fahrnow, A.; Muller, S.; O’Hagan, R. C.; Overington, J. P.; Owen, D. R.; Rosenberg, S. H.; Roth, B.; Ross, R.; Schapira, M.; Schreiber, S. L.; Shoichet, B.; Sundstrom, M.; Superti-Furga, G.; Taunton, J.; Toledo-Sherman, L.; Walpole, C.; Walters, M. A.; Willson, T. M.; Workman, P.; Young, R. N.; Zuercher, W. J. The promise and peril of chemical probes. Nat. Chem. Biol. 2015, 11, 536-541.

(10) Baell, J. B.; Holloway, G. A. New substructure filters for removal of pan assay interference compounds (PAINS) from screening libraries and for their exclusion in bioassays. J. Med. Chem. 2010, 53, 27192740.

(11) Shoichet, B. K. Screening in a spirit haunted world. Drug Discovery Today 2006, 11, 607-615.

(12) Walters, W. P.; Namchuk, M. Designing screens: how to make your hits a hit. Nat. Rev. Drug Discovery 2003, 2, 259-266.

(13) Rishton, G. M. Nonleadlikeness and leadlikeness in biochemical screening. Drug Discovery Today 2003, 8, 86-96.

(14) Simeonov, A.; Jadhav, A.; Thomas, C. J.; Wang, Y.; Huang, R.; Southall, N. T.; Shinn, P.; Smith, J.; Austin, C. P.; Auld, D. S.; Inglese, J. Fluorescence spectroscopic profiling of compound libraries. J. Med. Chem. 2008, 51, 2363-2371.

(15) Lea, W. A.; Simeonov, A. Fluorescence polarization assays in small molecule screening. Expert Opin. Drug Discovery 2011, 6, 17-32.

(16) Thorne, N.; Auld, D. S.; Inglese, J. Apparent activity in highthroughput screening: origins of compound-dependent assay interference. Curr. Opin. Chem. Biol. 2010, 14, 315-324.

(17) Ingolfsson, H. I.; Thakur, P.; Herold, K. F.; Hobart, E. A.; Ramsey, N. B.; Periole, X.; de Jong, D. H.; Zwama, M.; Yilmaz, D.; Hall, K.; Maretzky, T.; Hemmings, H. C., Jr.; Blobel, C.; Marrink, S. J.; Kocer, A.; Sack, J. T.; Andersen, O. S. Phytochemicals perturb membranes and promiscuously alter protein function. ACS Chem. Biol. 2014, 9, 1788-1798.

(18) Schneider, C.; Gordon, O. N.; Edwards, R. L.; Luis, P. B. Degradation of curcumin: From mechanism to biological implications. J. Agric. Food Chem. 2015, 63, 7606-7614.

(19) Feng, B. Y.; Shelat, A.; Doman, T. N.; Guy, R. K.; Shoichet, B. K. High-throughput assays for promiscuous inhibitors. Nat. Chem. Biol. 2005, 1, 146-148. 
(20) Coan, K. E.; Shoichet, B. K. Stoichiometry and physical chemistry of promiscuous aggregate-based inhibitors. J. Am. Chem. Soc. 2008, 130, 9606-9612.

(21) Feng, B. Y.; Simeonov, A.; Jadhav, A.; Babaoglu, K.; Inglese, J.; Shoichet, B. K.; Austin, C. P. A high-throughput screen for aggregation-based inhibition in a large compound library. J. Med. Chem. 2007, 50, 2385-2390.

(22) Jadhav, A.; Ferreira, R. S.; Klumpp, C.; Mott, B. T.; Austin, C. P.; Inglese, J.; Thomas, C. J.; Maloney, D. J.; Shoichet, B. K.; Simeonov, A. Quantitative analyses of aggregation, autofluorescence, and reactivity artifacts in a screen for inhibitors of a thiol protease. $J$. Med. Chem. 2010, 53, 37-51.

(23) Wolan, D. W.; Zorn, J. A.; Gray, D. C.; Wells, J. A. Smallmolecule activators of a proenzyme. Science 2009, 326, 853-858.

(24) Bisson, J.; McAlpine, J. B.; Friesen, J. B.; Chen, S. N.; Graham, J.; Pauli, G. F. Can invalid bioactives undermine natural product-based drug discovery? J. Med. Chem. 2016, 59, 1671-1690.

(25) Kilchmann, F.; Marcaida, M. J.; Kotak, S.; Schick, T.; Boss, S. D.; Awale, M.; Gönczy, P.; Reymond, J.-L. Discovery of a selective aurora a kinase inhibitor by virtual screening. J. Med. Chem. 2016, 59, $7188-7211$.

(26) Thorne, N.; Shen, M.; Lea, W. A.; Simeonov, A.; Lovell, S.; Auld, D. S.; Inglese, J. Firefly luciferase in chemical biology: a compendium of inhibitors, mechanistic evaluation of chemotypes, and suggested use as a reporter. Chem. Biol. 2012, 19, 1060-1072.

(27) Dahlin, J. L.; Walters, M. A. How to triage PAINS-full research. Assay Drug Dev. Technol. 2016, 14, 168-174.

(28) Baell, J. B. Feeling nature's PAINS: Natural products, natural product drugs, and pan assay interference compounds (PAINS). J. Nat. Prod. 2016, 79, 616-628.

(29) Baell, J. B. Observations on screening-based research and some concerning trends in the literature. Future Med. Chem. 2010, 2, 15291546.

(30) Baell, J. B. Screening-based translation of public research encounters painful problems. ACS Med. Chem. Lett. 2015, 6, 229-234.

(31) Dahlin, J. L.; Baell, J.; Walters, M. A. Assay interference by chemical reactivity. In Assay Guidance Manual; Sittampalam, G. S., Coussens, N. P., Nelson, H., Arkin, M., Auld, D., Austin, C., Bejcek, B.; Glicksman, M., Inglese, J., Iversen, P. W., Li, Z., McGee, J., McManus, O., Minor, L., Napper, A., Peltier, J. M., Riss, T., Trask, O. J., Jr., Weidner, J., Eds.; Eli Lilly \& Company and the National Center for Advancing Translational Sciences: Bethesda, MD, 2015.

(32) Ferreira, R. S.; Bryant, C.; Ang, K. K.; McKerrow, J. H.; Shoichet, B. K.; Renslo, A. R. Divergent modes of enzyme inhibition in a homologous structure-activity series. J. Med. Chem. 2009, 52, 50055008.

(33) Pouliot, M.; Jeanmart, S. Pan assay interference compounds (PAINS) and other promiscuous compounds in antifungal research. J. Med. Chem. 2016, 59, 497-503.

(34) Carlson, E. E.; May, J. F.; Kiessling, L. L. Chemical probes of UDP-galactopyranose mutase. Chem. Biol. 2006, 13, 825-837.

(35) Yang, J. J.; Ursu, O.; Lipinski, C. A.; Sklar, L. A.; Oprea, T. I.; Bologa, C. G. Badapple: promiscuity patterns from noisy evidence. J. Cheminf. 2016, 8, 29.

(36) Irwin, J. J.; Duan, D.; Torosyan, H.; Doak, A. K.; Ziebart, K. T.; Sterling, T.; Tumanian, G.; Shoichet, B. K. An aggregation advisor for ligand discovery. J. Med. Chem. 2015, 58, 7076-7087.

(37) Feng, B. Y.; Shoichet, B. K. A detergent-based assay for the detection of promiscuous inhibitors. Nat. Protoc. 2006, 1, 550-553.

(38) Sassano, M. F.; Doak, A. K.; Roth, B. L.; Shoichet, B. K. Colloidal aggregation causes inhibition of $\mathrm{G}$ protein-coupled receptors. J. Med. Chem. 2013, 56, 2406-2414.

(39) Owen, S. C.; Doak, A. K.; Wassam, P.; Shoichet, M. S.; Shoichet, B. K. Colloidal aggregation affects the efficacy of anticancer drugs in cell culture. ACS Chem. Biol. 2012, 7, 1429-1435.

(40) Babaoglu, K.; Simeonov, A.; Irwin, J.; Nelson, M.; Feng, B.; Thomas, C.; Cancian, L.; Costi, M.; Maltby, D.; Jadhav, A.; Inglese, J.; Austin, C.; Shoichet, B. Comprehensive mechanistic analysis of hits from high-throughput and docking screens against beta-lactamase. J. Med. Chem. 2008, 51, 2502-2511.

(41) Shoichet, B. K. Interpreting steep dose-response curves in early inhibitor discovery. J. Med. Chem. 2006, 49, 7274-7277.

(42) Fallahi-Sichani, M.; Honarnejad, S.; Heiser, L. M.; Gray, J. W.; Sorger, P. K. Metrics other than potency reveal systematic variation in responses to cancer drugs. Nat. Chem. Biol. 2013, 9, 708-714. 